\title{
Adult Oligodendroglial Tumor
}

National Cancer Institute

\section{Source}

National Cancer Institute. Adult Oligodendroglial T umor. NCI Thesaurus. Code C68691.

An oligodendrog lial tumor of the central nervous system occurring in adults. 